\title{
Facing the challenge of Innovation Ambidexterity: drivers and moderators in SME
}

\author{
Simona Popa ${ }^{1}$ and Pedro Soto-Acosta ${ }^{2, *}$ \\ ${ }^{1}$ Department of Financial Economics and Accounting, University of Murcia, Murcia, Spain \\ ${ }^{2}$ Department of Management and Finance, University of Murcia, Murcia, Spain
}

\begin{abstract}
This paper extends prior literature by analyzing the effect of technological, organizational and environmental factors on innovation ambidexterity and its influence on the performance of small- and medium-sized enterprises (SMEs) as well as the moderating effect environmental dynamism on this relationship. Building on the Technology-Organization-Environment theory and the Knowledge-Based View, this paper develops an integrative research model, which analyzes the network of relations using covariance-based structural equation modeling. Results show that information technology (IT) capability, knowledge management (KM) capability and environmental dynamism are positively associated with innovation ambidexterity. In addition, environmental dynamism is found to strengthen the positive effect of innovation ambidexterity on firm performance. Although many studies have highlighted that being ambidextrous is more challenging for SMEs than for their larger counterparts, these findings support the idea that innovation can be developed in an ambidextrous manner within a single SME as long as the firm is capable of creating a suitable organizational context and giving a prompt response to changes in the business environment.
\end{abstract}

Keywords: environmental dynamism; firm performance; IT capability; KM capability; structural equation modelling 


\section{Introduction}

In a continuously changing environment characterized by competitive intensity and the technological advance, the innovative capacity of firms is considered to be crucial for current and future competitiveness (Messeni Petruzzelli et al., 2015; Soto-Acosta et al., 2017). It is believed that the most successful firms are those who can balance explorative and exploitative innovation ambidextrously (Chang and Hughes, 2012). March (1991) proposes that exploitation and exploration are two fundamentally different learning activities between which firms divide their attention and resources. Despite the inherent challenges of maintaining a balance between the two activities, March (1991) believes that firms should pursue both types of activities.

In order to solve the paradox of ambidexterity recent research has presented a range of organizational alternatives, such as: i) structural separation by units (Benner \& Tushman, 2003; Puranam et al., 2006; Tushman et al., 2010), ii) temporal separation (Puranam et al., 2006; Siggelkow \& Levinthal, 2003), iii) inter-organizational specialization through joint ventures, alliances, acquisitions or outsourcing (Hill \& Birkinshaw, 2012; Lavie et al., 2010), and iv) shaping a suitable organization context (Gibson \& Birkinshaw, 2004; Gulati \& Puranam, 2009) that supports individual in taking autonomous decisions about dividing time between exploration and exploitation. Structural, temporal and inter-organizational solutions are based on the assumption that exploitative and explorative activities are absolutely incompatible (Chang \& Hughes, 2012), which is conceptually not consistent with the definition of ambidexterity. Moreover, recent research suggests that both types of innovation can be developed simultaneously within a single firm as long as firms are capable of creating a suitable organizational context (O'Reilly \& Tushman, 2008).

Although many studies have highlighted that being ambidextrous is more challenging for small and medium-sized enterprises (SMEs) than for their larger counterparts, the vast majority of studies has been conducted in large companies. In addition, prior research has mainly analyzed the direct relationship between ambidexterity and firm performance, with very few studies (e.g. Chang \& Hughes, 2012; He \& Wong, 2004; Patel et al., 2013) analyzing contingent factors. To address these issues, the objective of this study is to assess the effect of technological, organizational and enviromental (TOE) factors on innovation ambidexterity and its influence on the performance of manufacturing SMEs as well as if that relationship might be contingent on the environmental dynamism.

\section{Literature review and hypotheses}

\subsection{Innovation ambidexterity}

Organizational ambidexterity is framed in literature in terms of the competing demands for exploration and exploitation (Chang et al., 2011; Chang \& Hughes, 2012; Gupta et al., 2006; Raisch \& Birkinshaw, 2008). Ambidextrous organizations excel at exploiting existing 
competencies to enable incremental innovation and at exploring new opportunities to foster radical innovation (Andriopoulos \& Lewis, 2009). The former refers to relatively minor adaptations of existing products and business concepts, whereas the latter represents fundamental changes leading to a switch from existing products or concepts to completely new ones (Dewar \& Dutton, 1986). However, although most research studies on the topic decompose ambidexterity in terms of explorative and exploitative activities, there is some disagreement and considerable ambiguity in the literature regarding the operationalization of ambidexterity (Cao et al., 2009; Gupta et al., 2006).

Many researchers view exploration and exploitation as two ends of a single continuum, with unavoidable trade-offs. In line with this approach, to measure ambidexterity they subtract exploitation from exploration and use an absolute difference score (Cao et al., 2009; Chang \& Hughes, 2012; He \& Wong, 2004; Patel et al., 2013). A more dominant approach is to conceptualize exploration and exploitation as distinct and separable modes of activity and measure it by multiplying exploration and exploitation (Gibson \& Birkinshaw, 2004; Hill \& Birkinshaw, 2012; Kang \& Snell, 2009; Menguc \& Auh, 2008; Nemanich \& Vera, 2009). Alternative, other conceptualizations of ambidexterity include: (i) considering ambidexterity as a single factor with several exploration and exploitation items (Lubatkin et al., 2006); or (ii) viewing ambidexterity as a higher-order factor consisting of exploration and exploitation as single dimensions (Wang \& Rafiq, 2014). In line with most recent research, this study intends to measure innovation ambidexterity as a second-order construct consisting of two factors: (1) exploratory innovation, and (2) exploitative innovation.

Although these are sufficient arguments that emphasize on the difficulties of smaller firms in achieving innovation and/or organization ambidexterity, there are very few studies analyzing this phenomenon in the specific context of SMEs (Cao et al., 2009; Chang \& Hughes, 2012; Chang et al., 2011). Moreover, although there is abundant research on the relationship between innovation and/or organization ambidexterity and firm performance (Chang \& Hughes, 2012; Gibson \& Birkinshaw, 2004; He \& Wong, 2004; Patel et al., 2013), there is a need for further studies on the variables that moderate this relationship (Raisch \& Birkinshaw, 2008) As a dynamic capacity, innovation ambidexterity can not be, however, explained as a limited set of direct relationships of some factors on an organization's performance.

Existing research offers extensive theoretical argumentation about the potential of firms' information technology (IT) capability to drive significant innovations in business processes, products and services of firms (Del Giudice \& Della Peruta, 2016; Palacios-Marqués, et al., 2015, A, Soto-Acosta et al., 2016, Soto-Acosta et al., 2018). Besides technological factors, knowledge management (KM) has been defined in literature as a key determinant of innovation (Del Giudice et al., 2015; Martinez-Conesa et al., 2017; Soto-Acosta \& CegarraNavarro, 2016). In addition, environmental forces are considered to generate a great pressure in the establishment and outcome of innovation strategies (Jansen et al., 2009). In the same venue, firms' ability to deploy exploratory and exploitative innovations in an ambidextrous manner may depend on the development of diverse internal capabilities, such as IT and KM capabilities and, at the same time, on the quick response to external pressures such as environmental dynamism. Building on the TOE framework and the resource-based view, this study develops a research model to assess antecedents and outcomes of innovation 
ambidexterity in SMEs. The network of relations is illustrated in Figure 1 and is elaborated further in the following subsections.

Figure 1: Research model

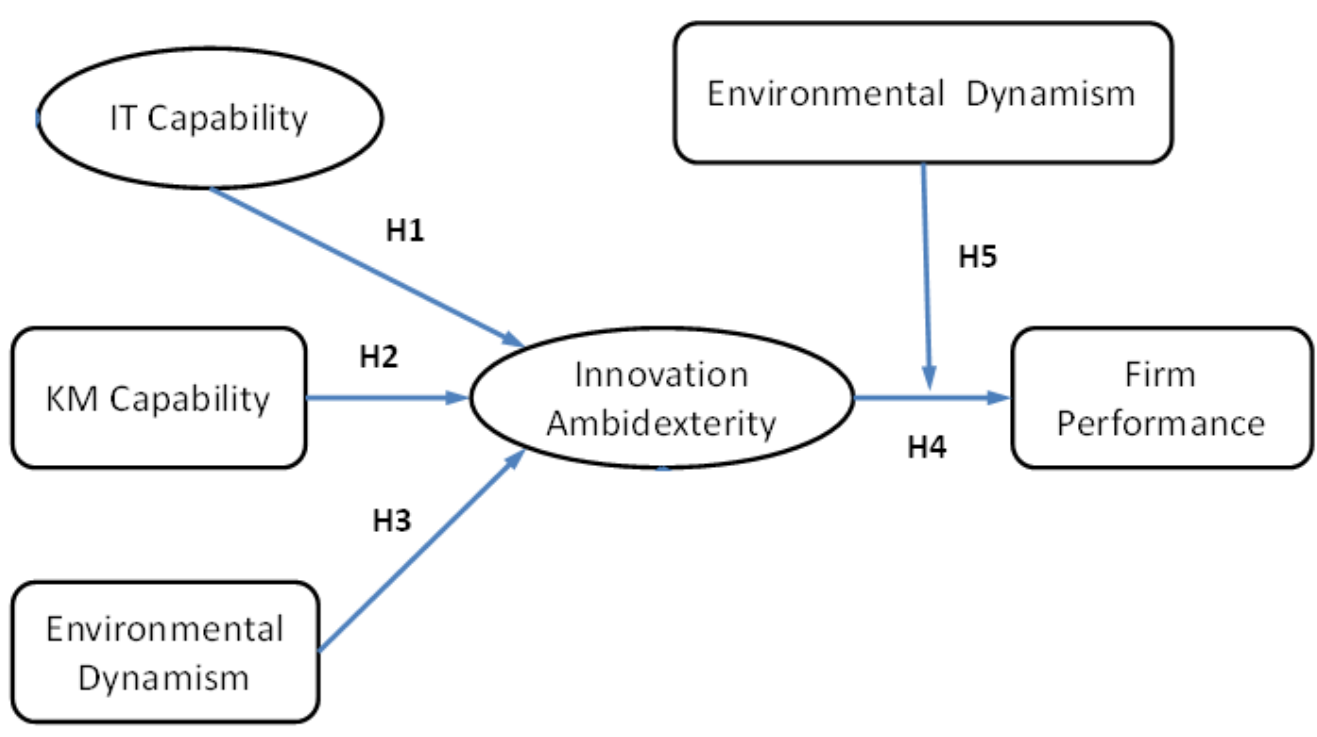

Source: own development

\subsection{Antecedents and outcomes of innovation ambidexterity}

The TOE framework conceives the context of adoption and implementation of technological innovations as consisting of three factors: the technological context, the organizational context and the environmental context. The technological context refers to the characteristics of the technological innovation, the organizational context describes characteristics of the organizations, and the environmental context implies characteristics of the environment in which the adopting organizations operate (Thong, 1999; Tornatzky \& Fleischer, 1990). The TOE framework has been extensively used as the theoretical framework to analyze factors which affect the adoption and use of different technological innovations (Chan et al., 2012; Lian et al., 2014; Palacios-Marqués, et al., 2015, B, Soto-Acosta et al., 2016, Soto-Acosta et al., 2018, Zhu et al., 2010).

Previous literature suggests that achieving innovation ambidexterity in SMEs depends on key resources and capabilities such as IT resources (Hadjimanolis, 2000). IT infrastructure by itself is typically imitable and should not be considered by firms a source of competitive advantage (Popa et al., 2016; Soto-Acosta \& Meroño-Cerdan, 2008). However, the ability of firms to mobilize and deploy IT resources in combination with other resources and capabilities, which is known as IT capability (Bharadwaj, 2000), could have positive outcomes (Chen et al., 2012; Soto-Acosta \& Meroño-Cerdan, 2008). The IT capability is expected to enhance data collection and processing to respond timely to market changes and to identify new business opportunities (Chaudhuri et al., 2011). In the same vein, IT capability may enhance the exploitation of capabilities for taking advantage of existing market opportunities and exploration of new opportunities to meet the challenges of emerging markets. Based on these arguments, the following hypothesis is proposed: 
H1. IT capability is positively associated with innovation ambidexterity.

Besides technological factors, knowledge management $(\mathrm{KM})$ has been identified in literature as a key determinant of innovation (Andreeva \& Kianto, 2011; Marqués \& Simón, 2006). The Knowledge-Based View (KBV) considers knowledge as the most strategic resource of a firm with potential to generate sustained competitive advantage and superior corporate performance because it is socially complex and, usually, difficult to imitate (Nickerson \& Zenger, 2004; Soto-Acosta et al., 2018). Organizational ambidexterity emerges from the contradictory knowledge processes of exploitation and exploration. Ambidextrous organizations excel at exploiting existing knowledge and experiences to enable incremental innovation and at exploring new knowledge to foster radical innovation (Andriopoulos \& Lewis, 2009). Although knowledge is a key resource with high strategic potential, firm must possess KM capabilities to asses and respond rapidly to competitors' actions (CegarraNavarro et al., 2016; Del Giudice \& Maggioni, 2014; Liao et al., 2011). Thus, firms that possess a greater KM capability are expected to be more efficient in balancing explorative and exploitative innovations in an ambidextrous manner. Building on these arguments, the following hypothesis is formulated:

$\mathrm{H} 2$. KM capability is positively associated with innovation ambidexterity.

Consistent with TOE framework and Contingency Theory, prior studies suggest that firms' innovation strategies are contingent on both internal and external factors (Gibson \& Birkinshaw, 2004; Jansen et al., 2006; Messeni Petruzzelli et al., 2009). In this vein, firms' ability to deploy exploratory and exploitative innovations in an ambidextrous manner may depend also on the quick response to external pressures such as the dynamism of the business environment. Environmental dynamism is characterized by technological changes, variations in customer preferences, changes in product demand and the unpredictability of change (Jansen et al., 2006). Dynamic business environments may push firms to engage in both exploitative and exploratory innovations simultaneously (Chang et al., 2011). As a consequence, in order to remain competitive in dynamic environments, firms must pursue exploitation activities and develop new products and services as the existing ones become rapidly obsolete (Jansen et al., 2006). At the same time, firms could develop exploitative innovations in order to cope with the threat of obsolescence and capitalize on previous exploratory efforts (Yang \& Li, 2011). Building on these arguments, the following hypothesis is posited:

H3. Environmental dynamism is positively associated with innovation ambidexterity.

Organization scholars have long argued that ambidexterity is a key driver of long-term firm performance. They believe that firms capable of simultaneously pursuing exploitation and exploration are more likely to achieve superior performance than firms emphasizing one at the expense of the other (Tushman \& O'Reilly, 1996). Firms' ability to compete successfully in the long run may thus be rooted in an ability to jointly pursue short-term efficiency and long-term innovation (Gibson \& Birkinshaw, 2004; Smith \& Tushman, 2005). In addition, successful exploration in one product or technological domain can enhance exploitative efforts in a complementary domain, which may result in an indirect effect of exploration on short-term performance through exploitation. Thus, the general agreement in 
this literature is that achieving ambidexterity enables a firm to enhance its performance and competitiveness (Cao et al., 2009). The following hypothesis incorporates our expectations.

H4. Innovation ambidexterity is positively associated with firm performance.

Furthermore, prior studies suggest that innovation effects are contingent on environmental factors (Jansen et al., 2006, 2009; Popa et al., 2017). In dynamic environments, exploratory innovation may generate a competitive advantage for firms that become first movers and explore new opportunities in emerging markets (Zahra \& Bogner, 2000). However, exploration may improve a firm's ability to renew its knowledge base but can undermine current operations at the expense of future opportunities (Gibson \& Birkinshaw, 2004). Conversely, a one-sided focus on exploitation may enhance short-term performance, but it can result in a competency trap, because these firms may not be able to respond adequately to market and technological changes (Ahuja \& Lampert, 2001). Although environmental dynamism might be seen like a threat, ambidextrous firms can take advantage of it as it continuously creates new business opportunities. Based on these arguments, the following hypothesis is proposed:

H5. Environmental dynamism strengthens the positive effect of innovation ambidexterity on firm performance.

\section{Methodology}

The target population of our study is formed by manufacturing SMEs from Spain with at least 20 employees for their research to ensure a minimum firm complexity (e.g. Carmeli \& Shteigman, 2010; Lubatkin et al., 2006; Simsek et al., 2005). The sample drawn was a random sample of companies from the respective sector population with the objective of fulfilling strata with respect to business size and business subsectors. In administering our survey, the questionnaire was assigned to senior and middle managers whose primary responsibilities are related to strategic innovation activities of the firms.

Data was collected in two stages. First, a pilot study was performed and, following that, a questionnaire was conducted. Fifteen SMEs were randomly selected from the SABI database to perform the pilot study. Based on their responses and subsequent interviews with participants in the pretest, minor modifications were made to the questionnaire. Responses from the firms that participated in the pilot study were not included in the final sample. The survey was administrated by using computer-assisted telephone interviewing (CATI) software. In total, a final dataset of 429 valid cases was obtained, yielding a response rate of 14.3 percent, which was comparable to other studies of similar scale. Data was examined for non-response-bias by comparing the characteristics of early and late participants in the study. The results of this comparison revealed that non-response bias does not represent a threat for the results obtained and their interpretation.

Measurement items were selected on the basis of a careful literature review. A description of the constructs and the associated indicators is provided in Appendix 1. All the variables used in the study were operationalized using multi-item instruments (seven-point Likert scales). Based on the scales developed by Tippins \& Sohi (2003) and Pérez-López \& Alegre (2012) a second-order construct was drew up to measure IT Capability. Overall, 10 item were 
adapted to measure the extent of use of IT to support firm operations and the degree of IT expertise along two dimensions: (1) IT-supported Operations; and (2) IT knowledge and budget. KM capability was operationalized by using the 10 items scale of Liao et al. (2011), which measured the extent of use of different KM practices across functional boundaries. Based on previous work of Jansen et al. (2006) a 3 item scale was used to measure environmental dynamism. In measuring Innovation ambidexterity, the scales from Jansen et al. (2006) and Chang \& Hughes (2012) were adapted to develop a second order construct including two dimensions: (1) exploratory innovation; (2) exploitative innovation. Drawing on Martin-Rojas et al. (2011) and Murray \& Kotabe (1999), 5 items were employed to evaluate firm performance (FP) relative to its main competitors along five key areas: ROA, ROE, ROS, market share and sales growth. In addition, a number of control variables that may influence firm performance were included (firm size, firm age and industry in which the firm operates). These variables are commonly used as controls by authors studying innovation (Chang et al., 2011).

The unidimensionality of the data set was assessed by different procedures. First an initial exploration of unidimensionality was done using principal component factor analyses. In each analysis the eigenvalues were greater than 1 and all factor loadings greater than 0.50 (with no substantial cross-loadings), lending preliminary support to a claim of unidimensionality in the constructs. Then, confirmatory factor analysis (CFA) was performed to establish the required convergent validity, discriminant validity, and reliability of the contructs. The measurement model presented a good fit to the data $(\chi 2(445)=909.988$; RMSEA $=0.049$; CFI $=0.96$; IFI $=0.96$; TLI $=0.95)$. All traditionally reported fit indexes were within the acceptable range. Construct reliability was assessed by using Bagozzi \& Yi's (1998) composite reliability index and Fornell \& Larcker's (1981) average variance extracted index. For all the measures both indices were higher than the evaluation criteria, namely 0.6 for composite reliability and 0.5 for the average variance extracted. Convergent validity assesses the consistency across multiple constructs. To assess the discriminant validity Forell \& Larcker's (1981) criterion was used. All constructs met this criterion, suggesting that the items share more variance with their respective constructs than with other constructs (diagonal elements of the correlation matrix in Table 2).

Table 1: Descriptive statistics and discriminant validity

\begin{tabular}{|l|r|r|r|r|r|r|r|}
\hline \multicolumn{1}{|c}{ Constructs } & Av. & SD & \multicolumn{1}{c|}{ (1) } & \multicolumn{1}{c|}{ (2) } & (3) & (4) & (5) \\
\hline 1. IT capability & 4,09 & 1,31 & $\mathbf{0 . 8 4}$ & & & & \\
\hline 2. KM capability & 4,17 & 1,47 & $0.70^{* *}$ & $\mathbf{0 . 8 6}$ & & & \\
\hline 3. Env. Dynamism & 4,11 & 1,72 & $0.29^{* *}$ & $0.28^{* *}$ & $\mathbf{0 . 8 3}$ & & \\
\hline 4. Innov. Ambidexterity & 4,53 & 1,30 & $0.48^{* *}$ & $0.50^{* *}$ & $0.47^{* *}$ & $\mathbf{0 . 8 4}$ & \\
\hline 5. Firm Performance & 4,52 & 1,20 & $0.36^{* *}$ & $0.36^{* *}$ & $0.21^{* *}$ & $0.29^{*}$ & $\mathbf{0 . 8 5}$ \\
\hline
\end{tabular}

Significance levels: $p<0.05^{*} ; p<0.01^{* *}$; na. Variance extracted is not applicable to the single-item constructs; Diagonal values in bold represent the square root of the AVE 


\section{icolityme}

$2^{\text {nd }}$ International Conference on Advanced Research in

MUNICH, GERMANY

BUSINESS, MANAGEMENT \& ECONOMICS

\section{Source: own development}

In addition, the extent of common method bias was assessed after data collection by using three distinct methods: the Harman's one-factor test (Podsakoff \& Organ, 1986), "unmeasured latent factor method" suggested by Podsakoff et al. (2003) and the correlation matrix (Table 2) did not indicate any highly correlated variables, while evidence of common method bias usually results in extremely high correlations ( $r>0.90$ ) (Bagozzi et al., 1991). In summary, these tests suggest that common method bias is not a serious threat in our study.

\section{Results}

This paper performs structural equation modeling (SEM) to test the hypotheses, using maximum likelihood estimation techniques to test the model. The fit of the model is satisfactory $(\chi 2(501)=948.595 ; \mathrm{RMSEA}=0.046 ; \mathrm{CFI}=0.95 ; \mathrm{IFI}=0.95 ; \mathrm{TLI}=0.94)$, suggesting that the nomological network of relations fits the data and the validity of the measurement scales (Churchill, 1979).

Figure 2 shows the standardized path coefficients with their respective significant levels. Hypotheses 1, 2 and 3 were confirmed (H1: 0.41, p<0.01; H2: 0.19, p<0.05; H3: 0.48, $\mathrm{p}<0.01)$. These results show that IT capability, KM capability and environmental dynamism have a positive and significant influence on innovation ambidexterity. In addition, Hypotheses 4 and 5 found support (H4: 0.53, p<0.01; H5: 0.12, p<0.05), indicating a positive and significant relationship between innovation ambidexterity and firm performance and that environmental dynamism strengthens the positive effect of innovation ambidexterity on firm performance.

Figure 2: Results

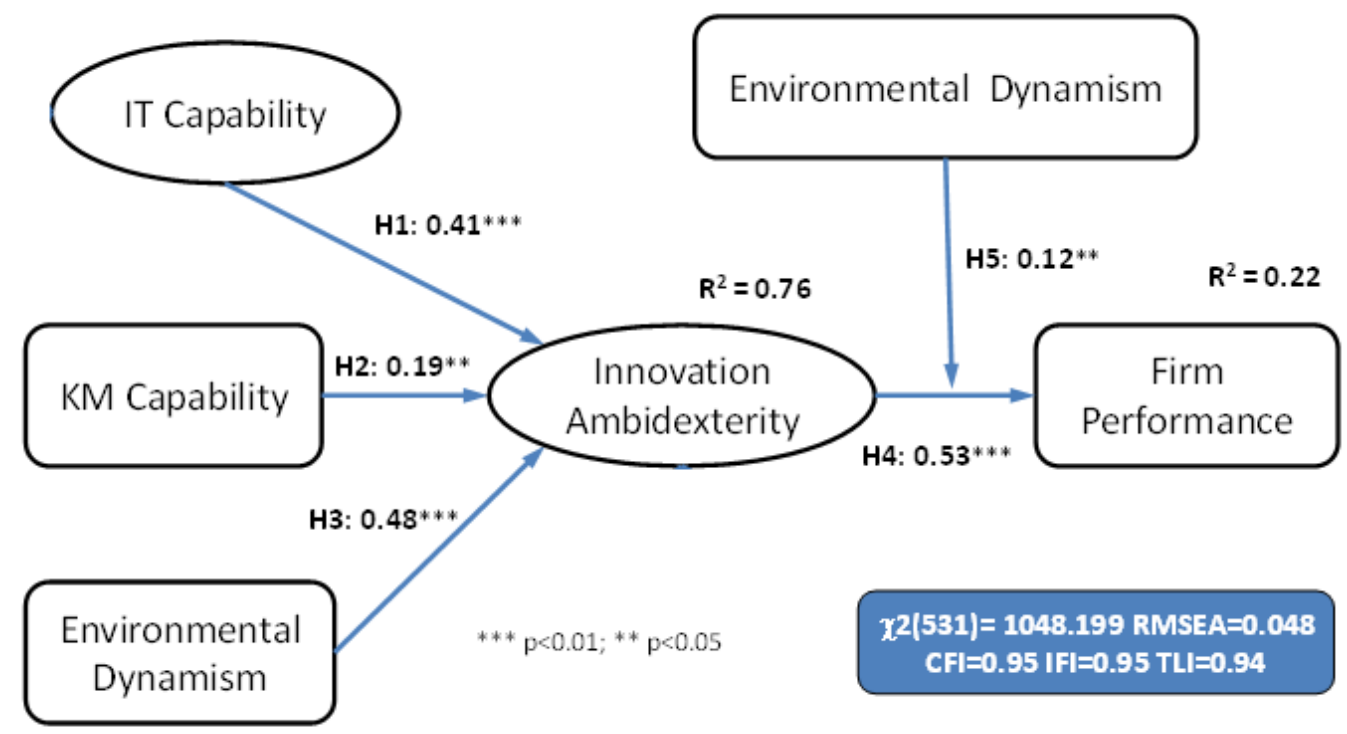

Source: own development 


\section{Discussion and conclusions}

This paper builds on the TOE framework and the RBV to shed light on the antecedents of innovation ambidexterity and its influence on firm performance, considering the moderating role of environmental dynamism. With regard to the technological context, the results revealed that IT capability have a positive effect on innovation ambidexterity. These findings are consistent with previous studies suggesting that aligning IT resources along with other critical resources at the firm's strategy level may enhance firm innovativeness (Chen et al., 2012; Soto-Acosta \& Meroño-Cerdan, 2008). In line with previous literature, our results show that show that KM capability have a positive influence on innovation ambidexterity, indicating that SMEs with strong KM capability are more capable of pursuing exploitative innovation and exploratory innovation in an ambidextrous manner. Regarding the environmental context, a positive relationship was found between environmental dynamism and innovation ambidexterity, being the strongest factor in our model. These findings provide empirical support for studies suggesting that dynamic environments may push enterprises to engage in both exploitative and exploratory innovations (Chang et al., 2011).

With respect to the consequences of innovation ambidexterity, the results suggest that innovation ambidexterity contributes positively to firm performance in SMEs, which confirms prior research suggesting that achieving ambidexterity enables a firm to enhance its performance and competitiveness (Cao et al., 2009). In addition, results show that environmental dynamism has a moderating role that strengthens the positive effect of innovation ambidexterity on firm performance. These findings partially support recent research, which suggests that: i) adopting an exploratory innovation perspective is more efficient in dynamic environments; while ii) following an exploitative innovation approach is more suitable in less dynamic but more competitive environments (Chang et al., 2011; Jansen et al., 2006). In this sense, results show that ambidextrous SMEs are more likely to outperform their competitors if they take advantage of the opportunities generated by dynamic environments.

The present study provides several important implications for managers. First, the study findings support the idea that innovation can be developed in an ambidextrous manner within a single firm as long as the firm is capable of creating a suitable organizational context. Firms should devote extra efforts to develop IT capabilities and KM capabilities because these capabilities are crucial when pursuing competing demands for exploration and exploitation. Second, our results show that firms' ability to deploy exploratory and exploitative innovations in an ambidextrous manner may depend not only on the development of internal capabilities, but also on the quick response to external pressures such as environmental dynamism. Thus, SMEs management should pay attention to both the internal and the external business context when balancing exploratory and exploitative innovations. Third, our findings also suggest that a dynamic environment creates opportunities for ambidextrous firms to outperform their competitors. Accordingly, ambidextrous SMEs should continuously scan and give a prompt response to changes in the business environment in order to generate sustained competitive advantages.

While the contributions of the present study are significant, it has some aspects which can be addressed in future research. First, the sample used was from Spain. It may be possible that 
the findings could be extrapolated to other countries, since economic and technological development in Spain is similar to other OECD member countries. However, in future research, a sampling frame that combines firms from different countries could be used in order to provide a more international perspective on the subject. Second, the key informant method was used for data collection. With this method the data reflects the opinions of only one person. Future studies could consider research designs that allow data collection from multiple respondents within an organization. Third, while IT capability, KM capability and environmental dynamism are found to be important drivers affecting innovation ambidexterity, future research could consider other potential factors such as organizational culture, leadership and open innovation. Fourth, firm performance measures are subjective in the sense that they were based on 7 point Likert-scale responses provided by managers. Thus, it could also be interesting to include objective indictors for measuring financial performance. Fifth, this research takes a static, cross-sectional picture of factors affecting innovation ambidexterity, which makes it difficult to address the issue of how this antecedents and their importance may change over time. A longitudinal study could enrich the findings. These suggestions should be taken into account in future studies to increase the validity of our findings.

\section{References}

[1] Ahuja, G. and Lampert, C. (2001). Entrepreneurship in the large corporation: A longitudinal study of how established firms create breakthrough inventions. Strategic Management Journal. 22 (6-7), pp. 521-543.

[2] Andreeva, T. and Kianto, A. (2011). Knowledge processes, knowledge intensity and innovation: a moderated mediation analysis. Journal of Knowledge Management. 15 (6), pp. 1016-1034.

[3] Andriopoulos, C. and Lewis, M.W. (2009). Exploitation-exploration tensions and organizational ambidexterity: Managing paradoxes of innovation. Organization Science. 20 (4), pp. 696-717.

[4] Bagozzi, R.P. and Yi, Y. (1998). On evaluation of structural equations models. Journal of the Academy of Marketing Science. 16 (1), pp. 74-94.

[5] Bagozzi, R.P., Yi, Y. and Phillips, L.W. (1991). Assessing construct validity in organizational research. Administrative Science Quarterly. 36 (3), pp. 421-458.

[6] Benner, M.J. and Tushman, M.L. (2003). Exploitation, exploration, and process management: the productivity dilemma revisited. Academy of Management Review. 28 (2), pp. 238-256.

[7] Cao, Q., Gedajlovic, E. and Zhang, H. (2009). Unpacking organizational ambidexterity: dimensions, contingencies, and synergistic effects. Organization Science. 20 (4), pp. 781796. 
[8] Carmeli, A. and Shteigman, A. (2010). Top management team behavioral integration in small-sized firms: A social identity perspective. Group Dynamics: Theory, Research, and Practice. 14 (4), pp. 318-331.

[9] Cegarra-Navarro, J-G., Soto-Acosta, P. and Wensley, A.K.P. (2016). Structured knowledge processes and firm performance: The role of organizational agility. Journal of Business Research, 69 (5), pp. 1544-1549.

[10]Chan, F.T.S., Chong, A.Y.-L. and Zhou, L. (2012). An empirical investigation of factors affecting e-collaboration diffusion in SMEs. International Journal of Production Economics. 138 (2), pp. 329-344.

[11]Chang, Y.Y., Hughes, M. and Hotho, S. (2011). Internal and external antecedents of SMEs' innovation ambidexterity outcomes. Management Decision. 49 (10), pp. 16581676.

[12]Chang, Y-Y. and Hughes, M. (2012). Drivers of innovation ambidexterity in small- to medium-sized firms. European Management Journal. 30 (1), pp. 1-17.

[13] Chaudhuri, S., Dayal, U. and Narasayya, V. (2011). An overview of business intelligence technology. Communications of the ACM. 54 (8), pp. 88-98.

[14]Churchill, G.A. (1979). A Paradigm for Developing Better Measures of Marketing Constructs. Journal of Marketing Research. 16 (1), pp. 64-73.

[15]Del Giudice, M. and Della Peruta, M.R. (2016). The impact of IT-based knowledge management systems on internal venturing and innovation: a structural equation modeling approach to corporate performance. Journal of Knowledge Management. 20 (3), pp. 484-498.

[16]Del Giudice, M. and Maggioni, V. (2014). Managerial practices and operative directions of knowledge management within inter-firm networks: A global view. Journal of Knowledge Management. 18 (5), pp. 841-846.

[17]Del Giudice, M., Della Peruta, M.R. and Maggioni, V. (2015). A model for the diffusion of knowledge sharing technologies inside private transport companies. Journal of Knowledge Management. 19 (3), pp. 611-625.

[18]Dewar, R.D. and Dutton, J.E. (1986). The adoption of radical and incremental innovations: An empirical analysis. Management Science. 32 (11), pp. 1422-1433.

[19]Fornell, C. and Larcker, F.D. (1981). Evaluating structural equation models with unobservable variables and measurement error. Journal of Marketing Research. 18 (1), pp. 39-50.

[20] Gibson, C.B. and Birkinshaw, J. (2004). The antecedents, consequences and mediating role of organizational ambidexterity. Academy of Management Journal. 47 (2), pp. 209226.

[21]Gulati, R. and Puranam, P. (2009). Renewal through reorganization: The value of inconsistencies between formal and informal organization. Organization Science. 20 (2), pp. 422-440. 
[22] Gupta, A.K., Smith, K.G. and Shalley, C.E. (2006). The interplay between exploration and exploitation. Academy of Management Journal. 49 (4), pp. 693-706.

[23] Hadjimanolis, A. (2000). A resource-based view of innovativeness in small firms. Technology Analysis and Strategic Management. 12 (2), pp. 263-281.

[24]He, Z.L and Wong, P.K. (2004). Exploration vs. exploitation: an empirical test of the ambidexterity hypothesis. Organization Science. 15 (4), pp. 481-494.

[25]Hill, S.A. and Birkinshaw, J. (2014). Ambidexterity and survival in corporate venture units. Journal of Management. 40 (7), pp. 1899-1931.

[26]Jansen, J.J.P., Van den Bosch, F.A.J. and Volberda, H.W. (2006). Exploratory innovation, exploitative innovation, and performance: effects of organizational antecedents and environmental moderators. Management Science. 52 (11), pp. 16611674.

[27] Jansen, J.J.P., Vera, D. and Crossan, M. (2009). Strategic leadership for exploration and exploitation: The moderating role of environmental dynamism. The Leadership Quarterly. 20 (1), pp. 5-18.

[28]Kang, S.C. and Snell, S.A. (2009). Intellectual capital architectures and ambidextrous learning: A framework for Human Resource Management. Journal of Management Studies. 46 (1), pp. 65-92.

[29]Lavie, D., Stettner, U. and Tushman, M.L. (2010). Exploration and exploitation within and across organizations. Academy of Management Annals. 4 (1), pp. 109-155.

[30]Lian, J., Yen, D. and Wang, Y. (2014). An exploratory study to understand the critical factors affecting the decision to adopt cloud computing in Taiwan hospital. International Journal of Information Management. 34 (1), pp. 28-36.

[31]Liao, C., Chuang, S. H. and To, P. L. (2011). How knowledge management mediates the relationship between environment and organizational structure. Journal of Business Research. 64 (7), pp. 728-736.

[32]Lubatkin, M.H., Simsek, Z., Ling, Y. and Veiga, J.F. (2006). Ambidexterity and performance in small- to mediumsized firms: the pivotal role of top management team behavioral integration. Journal of Management. 32 (5), pp. 646-672.

[33] March, J.G. (1991). Exploration and exploitation in organizational learning. Organization Science. 2 (1), pp. 71-87.

[34] Marqués, D.P. and Simón, F.J.G. (2006). The effect of knowledge management practices on firm performance. Journal of Knowledge Management. 10 (3), pp. 143-156.

[35] Martinez-Conesa, I.; Soto-Acosta, P. and Carayannis, E.G. (2017). On the path towards open innovation: Assessing the role of knowledge management capability and environmental dynamism in SMEs. Journal of Knowledge Management, 21 (3), pp. 553570 . 
[36] Menguc, B. and Auh, S. (2008). The asymetric moderating role of market orientation on the ambidexterity-firm performance relationship for prospectors and defenders. Industrial Marketing Management. 37 (4), pp. 455-470.

[37] Messeni Petruzzelli, A., Albino, V. and Carbonara, N. (2009). External knowledge sources and proximity. Journal of Knowledge Management. 13 (5), pp. 301-318.

[38] Messeni Petruzzelli, A., Rotolo, R. and Albinoa, V., (2015). Determinants of patent citations in biotechnology: An analysis of patent influence across the industrial and organizational boundaries. Technological Forecasting and Social Change. 91, pp. 208221.

[39] Murray, J.Y. and Kotabe, M. (1999). Sourcing strategies of US service companies: A modified transaction-cost analysis. Strategic Management Journal. 20 (9), pp. 791-809.

[40] Nemanich, L.A. and Vera, D. (2009). Transformational leadership and ambidexterity in the context of an acquisition. The Leadership Quarterly. 20 (1), pp. 19-33.

[41] Nickerson, J. and Zenger, T. (2004). A knowledge-based theory of the firm: the problem solving perspective. Organization Science. 15 (6), pp. 617-632.

[42] O'Reilly, C.A. and Tushman, M.L. (2008). Ambidexterity as a dynamic capability: resolving the innovator's dilemma. Research in Organizational Behavior. 28 (1), pp. 185-206.

[43]Palacios-Marqués, D., Merigó, J.M. and Soto-Acosta, P. (2015, A). Online social networks as an enabler of innovation in organizations. Management Decision. 53 (9), pp. 1906-1920.

[44]Palacios-Marqués, D., Soto-Acosta, P. and Merigó, J.M. (2015, B). Analyzing the effects of technological, organizational and competition factors on Web knowledge exchange in SMEs. Telematics and Informatics. 32 (1), pp. 23-32.

[45]Patel, P.C., Messersmith, J.G. and Lepak, D.P. (2013). Walking the Tightrope: An Assessment of the Relationship between High-Performance Work Systems and Organizational Ambidexterity. Academy of Management Journal. 56 (5), pp. 1420-1442.

[46]Pérez-López, S. and Alegre, J. (2012). Information technology competency, knowledge processes and firm performance. Industrial Management \& Data Systems. 112 (4), pp. 644-662.

[47] Podsakoff, P.M. and Organ, D.W. (1986). Self-reports in Organizational Research: Problems and Prospects. Journal of Management. 12 (4), pp. 531-544.

[48] Podsakoff, P.M., MacKenzie, S.B., Lee, J.Y. and Podsakoff, N.P. (2003). Common method biases in behavioral research: A critical review of the literature and recommended remedies. Journal of Applied Psychology. 88 (5), pp. 879-903.

[49]Popa, S., Soto-Acosta, P. and Loukis, E. (2016). Analyzing the complementarity of web infrastructure and eInnovation for business value generation. Program. 50 (1), pp. 118134. 
[50]Popa, S.; Soto-Acosta, P. \& Martinez-Conesa, I. (2017). Antecedents, moderators, and outcomes of innovation climate and open innovation: An empirical study in SMEs. Technological Forecasting and Social Change, 118 (1), pp. 134-142.

[51]Puranam, P., Singh, H. and Zollo, M. (2006). Organizing for innovation: managing the coordination-autonomy dilemma in technology acquisitions. Academy of Management Journal. 49 (2), pp. 263-280.

[52]Raisch, S. and Birkinshaw, J. (2008). Organizational ambidexterity: Antecedents, outcomes, and moderators. Journal of Management. 34 (3), pp. 375-409.

[53] Siggelkow, N. and Levinthal, D.A. (2003). Temporarily divide to conquer: Centralized, decentralized, and reintegrated organizational approaches to exploration and adaptation. Organization Science. 14 (6), pp. 650-669.

[54] Simsek, Z., Veiga, J.F., Lubatkin, M. and Dino, R.N. (2005). Modeling the multilevel determinants of top management team behavioral integration. Academy of Management Journal. 48 (1), pp. 69-84.

[55]Smith, W.K. and Tushman, M.L. (2005). Managing strategic contradictions: A top management model for managing innovation streams. Organization Science. 16 (5), pp. 522-536.

[56] Soto-Acosta, P. and Cegarra-Navarro, J.G. (2016). New ICTs for Knowledge Management in Organizations. Journal of Knowledge Management. 20 (3), pp. 417-422.

[57] Soto-Acosta, P. and Meroño-Cerdan, A.L. (2008). Analyzing e-business value creation from a resource-based perspective. International Journal of Information Management. 28 (1), pp. 49-60.

[58] Soto-Acosta, P., Popa, S. and Perez-Gonzalez, D. (2018). An investigation of the effect of electronic business on financial performance of Spanish manufacturing SMEs. Technological Forecasting and Social Change. 136, pp. 355-362.

[59] Soto-Acosta, P., Popa, S. and Palacios-Marqués, D. (2016). E-business, organizational innovation and firm performance in manufacturing SMEs: an empirical study in Spain. Technological and Economic Development of Economy. 22 (6), pp. 885-904.

[60] Soto-Acosta, P., Popa, S. and Palacios-Marqués, D. (2017). Social web knowledge sharing and innovation performance in knowledge-intensive manufacturing SMEs. Journal of Technology Transfer. 42 (2), pp. 425-440.

[61] Thong, J.Y.L. (1999). An integrated model of information systems adoption in small businesses. Journal of Management Information Systems. 15 (4), pp. 187-214.

[62] Tippins, M.J. and Sohi, R.S. (2003). IT competency and firm performance: is organizational learning a missing link?. Strategic management journal. 24 (8), pp. 745 761.

[63] Tornatzky, L.G. and Fleischer, M. (1990). The process of technological innovation. Lexington: Lexington Books. 


\section{icolityme}

$2^{\text {nd }}$ International Conference on Advanced Research in

[64]Tushman, M.L. and O'Reilly, C.A. (1996). Ambidextrous organizations: Managing evolutionary and revolutionary change. California Management Review. 38 (4), pp. 8-30.

[65] Tushman, M.L., Smith, W.K., Wood, R.C., Westerman, G. and O'Reilly, C. (2010). Organizational designs and innovation streams. Industrial and Corporate Change. 19 (5), pp. 1331-1366.

[66] Wang, C.L. and Rafiq, M. (2014). Ambidextrous organizational culture, contextual ambidexterity and new product innovation: A comparative study of UK and Chinese high-tech firms. British Journal of Management. 25 (1), pp. 58-76.

[67] Yang, T.T. and Li, C.R. (2011). Competence exploration and exploitation in new product development: The moderating effects of environmental dynamism and competitiveness. Management Decision. 49 (9), pp. 1444-1470.

[68]Zahra, S.A. and Bogner. W.C. (2000). Technology strategy and software new venture's performance: Exploring effect of the competitive environment. Journal of Business Venturing. 15 (2), pp. 135-173

[69]Zhu, Y., Li, Y., Wang, W. and Chen, J. (2010). What leads to the post-implementation success of ERP? An empirical study of the chinese retail industry. International Journal of Information Management. 30 (3), pp. 265-276. 